\title{
Knowledge, Attitude and Practice of Breast Self- examination among Nursing Students in Hong Kong: A Cross-sectional Study
}

\author{
Shuk Yu Maria HUNG \\ School of Nursing \\ Tung Wah College \\ Hong Kong, China \\ mariahung@twc.edu.hk \\ Kam Ki Stanley LAM \\ School of Nursing, \\ Tung Wah College \\ Hong Kong, China \\ stanleylam@twc.edu.hk
}

\author{
Wing Yan FUNG \\ School of Nursing \\ Tung Wah College \\ Hong Kong, China \\ 12001071@twc.edu.hk \\ Kurt NAN \\ School of Nursing \\ Tung Wah College \\ Hong Kong, China \\ kurtnan@twc.edu.hk
}

\begin{abstract}
Breast cancer is a global public health concern. Currently, the crude incidence rate of breast cancer in Hong Kong is increasing. Although breast self-examination (BSE) is an effective screening method which able to reduce mortality rates, only a few women perform it monthly. As nurses play a significant role in promoting BSE, this study aims to study the knowledge, attitude, and practice of BSE for nursing students. A crosssectional design was employed, and 372 nursing students participated in this study. Results reveal that even BSE are compulsory in nursing curriculum, poor knowledge ("don't know" $46.9 \%$, incorrect $9.4 \%$.), poor attitude $($ mean $=\mathbf{2 4 . 2 9}$, SD $=3.49$ ) and limited practice (mean $=7.69, \mathrm{SD}=4.66$ ) were found. Regression analysis support that knowledge and attitude predict practice of BSE. It is important to promote and build up the awareness of BSE to nursing students by enhancing their knowledge and attitude.
\end{abstract}

Keywords-breast cancer; breast self-examination; knowledge; attitude; practice; nursing students

\section{INTRODUCTION}

Breast cancer is a life threating illness across all social background in global [1]. Historically, the western white population had high incidence rates of breast cancer. However, the rate among Asian population has increased rapidly in recent years [2]. Across various Asian countries, it was reported that Hong Kong has the highest crude incident rate of breast cancer $[3,4]$. In addition, the age-standardized incidence rates have also been increasing from 38.2 per 100000 in 1990 to 46.6 per 100 000 in 2000 and further increased to 63.8 per 100000 in 2015 $[4,5]$. This lead breast cancer becomes the highest incidence rate of cancer for women which has overtaken colorectal cancer in Hong Kong.

As breast cancer become a significant public health concern in Hong Kong, early detection through screening is important prevention. It can significantly speed up the process of cancer treatment, reduce mortality, and improve women's overall quality of life. Azaiza and Cohen [6] ascertain early detection of breast cancer can decrease mortality rates by $25-30 \%$. Therefore, Hong Kong Breast Cancer Foundation recommends the following plan for breast cancer screening for women: (1) mammography should be performed every 2 years for ages 50 to 69 ; (2) clinical breast examination should be conducted once a year for age over 40; (3) breast self- examination (BSE) should be performed monthly for age over 20 [7]. Compare with various screening methods, BSE is a simple, low cost, noninvasive and no special tool requirement. This effective diagnostic method only takes five minutes to perform independently without relying on a health care professional [8]. American Cancer Society [9] assure women who correctly practice BSE monthly are more likely to detect a lump in the early stage which leads to early treatment and a better survival rate.

Although BSE is effective in preventing breast cancer, it was reported that such method was not adopted by the majority of women as a usual practice [10]. Evidence revealed that breast cancer screening behaviors among Chinese women are relatively low when compared with women in Western countries such as Austria, Canada, and the United States [11, 12]. Similarly, the majority of Hong Kong women (90\%) had received information regarding the practice of $\mathrm{BSE}$, however merely one-third of them claimed that they would perform BSE regularly in a monthly basis as suggested [14]. It was suggested in the literature that the key factor which influence BSE practice among Chinese women is their cultural beliefs [15]. For instance, Chinese believe the cause of breast cancer is a fate which makes screening become meaningless. When they feel asymptomatic, they believe there is no reason to suspect any disease which ignores any screening [16]. It is significant to motivate general public women to regularly carry out BSE to curtail the increasing mortality rate from breast cancer [17].

Nurses as a group of health care professionals, they have more relations and constant communication with patients than other health care professionals [18]. They can provide 
promotion and correct health information to the public. Especially for BSE, women are more comfortable in asking questions to female nurses. Therefore, female nurses play a significant responsibility in promoting and encouraging the compliance of BSE [19]. It is believed that knowledge and attitude of nurses regarding BSE which affect their own behaviors are important for them so as to play this role properly. Therefore, nursing students must be equipped with adequate knowledge about BSE, perform BSE correctly while in college, so they can educate the public after graduation [20].

Despite the importance of nursing students in the role of promoting BSE, limited studies focus on this topic. For Korea nurses, most of them recognize the importance of BSE. However, only $58.9 \%$ experience BSE. BSE practice level is relative low which only $20.2 \%$ have recommended BSE to their clients [21]. For nursing students, BSE is rarely performed. Studies find only $66 \%$ of the nursing students in Saudi Arabia and $1.3 \%$ of Egyptian students conduct BSE [22, 23]. Currently, there are no available data about BSE knowledge, attitude, and practice of Hong Kong nursing students, which has the highest crude incident rate among Asian cities. Therefore, this study aims to determine the knowledge, attitude, and practice of nursing students regarding BSE and to establish baseline data for further research as well as for new curricular strategies for breast cancer prevention.

\section{METHODS}

This is a cross-sectional study in Hong Kong. There were 372 students (age mean $=20.37, \mathrm{SD}=1.46$ ) participated in this study. Inclusion criteria include (1) female and (2) nursing students in tertiary college. The questionnaire consisted of demography information such as age, education level, any history of breast cancer, any family members/recognize people who have breast cancer. Other parts of questionnaire measures knowledge, attitude and practice of BSE which is developed by Rosmawati [24]. There are 15 items covering on the sign of breast cancer and method on performing BSE for knowledge which categorical responses (True/False/Don't know) were applied. There are also 13 items measuring attitude and seven items measuring practice of BSE which 5-point Likert scale was applied from strongly disagree (0) to strongly agree (4) and never (0) to always (4) representatively. The higher scores refer to a better attitude and frequency of BSE practice.

\section{RESULTS}

Data were analyzed by IBM SPSS version 23.0. For knowledge, the highest correct items are "Need to observe for unusual change in shape and size of breast" (73.9\% correct); "Use finger pulps to examine any lump or thickening of the skin" $(61.3 \%$ correct) and "BSE should be done in front of the mirror" (56.5\% correct). The lowest correct items are "BSE must be done between day 7 until day 10 after menses" (14.8\% correct); "BSE should be done every two months" (22.3\% correct); "BSE can be done in supine position" (27.2\% correct). The correct average percentage is $43.6 \%$, "don't know" percentage is $46.9 \%$, the incorrect percentage is $9.4 \%$.

For attitude, the highest score items are "All women should do BSE" (mean = 2.84); "I really care about my breast" (mean = 2.47); "Doing BSE makes me feel so funny" (mean = 2.41, reversed). The lowest score items are "Doing BSE is wasting time" $($ mean $=1.21$, reversed); "Feel uncomfortable can't do BSE once a month" (mean = 1.33); "Always search for information regarding BSE from the internet, magazine and newspaper" $($ mean $=1.45)$. The total attitude score is mean $=$ 24.29, $\mathrm{SD}=3.49$.

For practice, the highest score items are "If notice any breast abnormality, straightly go to public healthcare" ( "Have been taught on BSE by health staffs" (mean = 1.09); "Avoid from learning the correct method of BSE" ( mean = 1.06, reversed). The lowest score items are "Advice friends to do BSE" (mean $=0.80)$; "Discuss the importance of BSE with friends" $($ mean $=0.80)$; "Do BSE once a month" $($ mean $=0.87)$. The total practice score is mean $=7.69, \mathrm{SD}=4.66$.

The hierarchical multiple regression revealed that participants' knowledge and attitude significantly contribute to practice $(\mathrm{F}(2,369)=9.32, \mathrm{p}<.01)$. The regression model explained $4.3 \%$ of the variation, and the standardized beta for knowledge and attitude are 0.17 and 0.13 representatively. 
Table 1. Knowledge of BSE

\begin{tabular}{|c|c|c|c|}
\hline Question items & $\underline{\text { True }}$ & $\frac{\text { I don't }}{\underline{\text { know }}}$ & $\underline{\text { False }}$ \\
\hline 1. BSE should be done every month & $22.3 \%$ & $61.0 \%$ & $16.7 \%$ \\
\hline 2. BSE must be done between day 7 until day 10 after menses & $14.8 \%$ & $71.5 \%$ & $13.7 \%$ \\
\hline 3. BSE should be done in front of the mirror & $56.5 \%$ & $29.8 \%$ & $13.7 \%$ \\
\hline 4. Undress until the waist when doing the BSE & $53.2 \%$ & $37.9 \%$ & $8.9 \%$ \\
\hline $\begin{array}{l}\text { 5. Hands should be raised up alternately above the head when doing the BSE in front of } \\
\text { the mirror }\end{array}$ & $49.5 \%$ & $41.1 \%$ & $9.4 \%$ \\
\hline 6. $\quad$ BSE should be done from the front view only* & $14.2 \%$ & $38.7 \%$ & $47.0 \%$ \\
\hline 7. BSE can be done in supine position & $27.2 \%$ & $50.8 \%$ & $22.0 \%$ \\
\hline 8. Palpate on the right breast while left sided lying when doing the BSE & $27.7 \%$ & $62.1 \%$ & $10.2 \%$ \\
\hline 9. Use finger pulps to examine any lump or thickening of the skin & $61.3 \%$ & $35.2 \%$ & $3.5 \%$ \\
\hline 10. BSE can be done using a vertical strip and circular technique & $43.8 \%$ & $54.8 \%$ & $1.3 \%$ \\
\hline 11. Need to press on the nipple to check any unusual discharge & $54.3 \%$ & $36.8 \%$ & $8.9 \%$ \\
\hline 12. BSE include armpit examination to check for any lump & $40.9 \%$ & $57.3 \%$ & $1.9 \%$ \\
\hline 13. Need to observe for unusual change in shape and size of the breast & $73.9 \%$ & $22.8 \%$ & $3.2 \%$ \\
\hline 14. Retraction of the nipple is the warning signs that should be observed & $38.7 \%$ & $55.4 \%$ & $5.9 \%$ \\
\hline 15. Lump is the early sign for cancer & $46.5 \%$ & $45.2 \%$ & $8.3 \%$ \\
\hline 16. Mean & $43.8 \%$ & $46.9 \%$ & $9.4 \%$ \\
\hline
\end{tabular}

*Negative items: scoring was reversed

Table 2. Attitudes of BSE

\begin{tabular}{|c|c|c|}
\hline Question items & $\underline{\text { Mean }}$ & $\underline{\mathrm{SD}}$ \\
\hline 1. Doing BSE is wasting time* & 1.21 & 0.79 \\
\hline 2. Feel uncomfortable can't do BSE once a month & 1.33 & 0.76 \\
\hline 3. Always search for information regarding BSE from the internet, magazine and newspaper & 1.45 & 0.76 \\
\hline 4. Doing BSE make me feel unpleasant* & 1.47 & 0.8 \\
\hline 5. Avoid doing BSE because worry to get breast cancer * & 1.57 & 0.94 \\
\hline 6. Discuss with my friends about BSE & 1.63 & 0.81 \\
\hline 7. BSE will be embarrassing to me* & 1.73 & 0.93 \\
\hline 8. I'm not afraid to think about the breast cancer & 1.96 & 0.94 \\
\hline 9. Interested to do BSE & 2.09 & 0.71 \\
\hline 10. If there is a lump, I prefer to get treatment from traditional healer* & 2.13 & 0.9 \\
\hline 11. Doing BSE makes me feel so funny* & 2.41 & 0.78 \\
\hline 12. I really care about my breast & 2.47 & 0.72 \\
\hline 13. All women should do BSE & 2.84 & 0.86 \\
\hline 14. Total Attitude score & 24.29 & 3.49 \\
\hline
\end{tabular}

*Negative items: scoring was reversed 
Table 3. Practices of BSE

\begin{tabular}{|l|c|c|}
\hline \multicolumn{1}{|c|}{ Question items } & Mean & \multicolumn{1}{|c|}{ SD } \\
\hline 1. Advice friends to do BSE & 0.80 & 1.02 \\
\hline 2. Discuss the importance of BSE with friends & 0.80 & 0.94 \\
\hline 3. Do BSE once a month & 0.87 & 0.94 \\
\hline 4. Parents or partner always advice to do BSE & 0.91 & 1.02 \\
\hline 5. Avoid from learning the correct method of BSE* & 1.06 & 0.94 \\
\hline 6. Have been taught on BSE by health staffs & 1.09 & 1.05 \\
\hline 7. If notice any breast abnormality, straightly go to public healthcare & 2.17 & 1.16 \\
\hline 8. Total Practice score & 7.69 & 4.66 \\
\hline
\end{tabular}

*Negative items: scoring was reversed

\section{DISCUSSION}

To our knowledge, this is the first study of Hong Kong nursing students' knowledge, attitude and practice of BSE. It reports the current phenomenon of BSE which is relatively poor. Regression analysis further provides the relationship between knowledge, attitude, and practice of BSE.

Although BSE training for nursing students are compulsory in Hong Kong, on average only $43.8 \%$ adequate necessary knowledge of BSE. $46.9 \%$ and $9.4 \%$ of them answered don't know and incorrect answer representatively. They are especially weak in the appropriate time, and frequency of BSE such as "BSE must be done between day 7 until day 10 after menses". These suggest nursing students' BSE knowledge are insufficient. In fact, studies reveal that BSE knowledge is not sufficient among the teenagers in Turkey where $13.2 \%$ only know about the appropriate time for BSE and $26.6 \%$ have the correct response to the procedure of BSE [25]. Lack of knowledge assures a considerable ignorance regarding breast cancer in this age group. It is possible that Chinese community is shameful about the topic of sex and breast cancer. Perhaps an open discussion or venues should be done for promoting BSE which women have more channel in acquiring breast cancer information. Media also play a significant role in health promotion in Hong Kong. Therefore, proactive effort should be made in media to create breast cancer awareness.

Surprisingly, the attitude of BSE in nursing students are also poor. They believe "doing BSE is wasting time" and "Feel uncomfortable can't do BSE once a month". They total attitude score (mean $=24.29)$ is much lower than Malaysia suburban women $($ mean $=37.10)$ [24]. Probably teenagers believe breast cancer is still far away from their age group. Therefore, they do not perceive the necessary of BSE. Besides, attitude is one of the significant predictors of the practice of BSE. Improvement on the attitude of breast cancer should be made in the curriculum of nursing students.

For the practice of BSE, nursing students have limited practice. The lowest score item includes "Do BSE once a month". Moreover, they have a limited discussion about BSE among their friends. These imply breast cancer is still a taboo for Chinese. Besides, it further implies their limited willingness in promoting BSE for future patients. Consistent with other global studies, for nursing students in Palestine, only $4.1 \%$ always practice BSE monthly, and $62.9 \%$ reported they never performed it [25]. Al-Abadi et al. [26] also suggest $3 \%$ of female university students were performing BSE monthly and $22.7 \%$ of the students were performing BSE irregularly. Other studies found only $39.5 \%$ nursing students perform BSE [27].

\section{CONCLUSION}

Given the escalating incidence rates of breast cancer in Hong Kong, the present study has identified an urgent need to emphasize the importance of breast cancer screening and reinforce such practice among Hong Kong population. In order to enhance the compliance and willingness of BSE practice among Hong Kong nursing students, the findings of the present study suggest that it is of paramount importance to bolster their knowledge and attitudes towards BSE through health education. This information might offer insight into the further development of breast health education programs and breast cancer screening campaigns.

\section{ACKNOWLEDGMENT}

We would like to express our sincere gratitude to $\mathrm{Dr}$ Nik Rosmawati Nik Husain who granted approval in using the questionnaire for data collection. Besides, we also thank KM Leung, LK Cheung, LK Lo, SM Tsoi, YC Wong, and YY Pang for their contribution in the study as well as the nursing students who participated the study.

\section{REFERENCES}

[1] D. Parkin and L. Fernandez, "Use of statistics to assess the global burden of breast cancer," Breast J, vol. 12, no. 70, pp. 80, 2006.

[2] D. Parkin, F. Bray F and J. Ferau J, "Global cancer statistics," CA Cancer J Clin, vol. 55, no. 74, pp. 108, 2005.

[3] G. Agarwal, P. Pradeep, and V. Aggarwal, "Spectrum of breast cancer in Asian women," World J Surg, vol. 31, pp. 1031-1040, 2007.

[4] Hospital Authority. Hong Kong Cancer Statistics, 2015. [Online]. Available:

http://www3.ha.org.hk/cancereg/pdf/factsheet/2015/breast_2015.pdf [Accessed Apr. 24, 2018.

[5] A. Kwong, P. Cheung, and S. Chan, "Breast cancer in Chinese women younger than age 40: are they different from their older counterparts?," World J Surg, vol. 32, pp. 2554-2561, 2008. 
[6] A. Azaiza and M. Cohen, "Health beliefs and rate of breast cancer screening among Arab women," J Women's Health, vol. 15, no. 5, pp. 520-530.

[7] K. D. Beydağ and B. Yürügen, "The Effect of Breast Self- Examination (Bse) Education Givento Midwifery Students on Their Knowledge and Attitudes," Asian Pacific J Cancer Prev, vol. 11, pp. 1761-1764, 2010.

[8] E. Wong-Kim and C. Wang, "Breast self-examination among Chinese immigrant women," Health Educ Behav, vol. 33, no. 5, pp. 580-590, 2006.

[9] American Cancer Society, American Cancer Society recommendations for early breast cancer detection, 2014. [Online] Available: http:// www.cancer.org/cancer/breastcancer/detailedguide/breastcancerdetection [Accessed Apr. 24, 2018].

[10] L. L. Stamler, B. Thomas and K. Lafreniere, "Working women identify influences and obstacles to breast health practices," Oncol Nurse Forum, vol. 27, pp. 810-835, 2000.

[11] C. Kwok, J. Fethney and K. White, "Breast cancer screening practices among Chinese-Australian women," Eur J Oncol Nurs, vol. 16, pp. 247 252, 2012.

[12] L. Todd, E. Harvey and L. Hoffman-Goetz, "Predicting breast and colon cancer screening among English-as-a-second-language older Chinese immigrant women to Canada," J Cancer Educ,vol. 26, no. 1, pp. 161-169, 2010.

[13] C. Kwok and D. Y. Fong, "Breast cancer screening practices among Hong Kong Chinese women," Cancer Nursing, vol. 37, no. 1, pp. 59-65, 2014.

[14] D. Leung, A. Leung and I. Chi, "Breast and colorectal cancer screening and associated correlates among Chinese older women," Asian Pac J Cancer Prev, vol. 13, pp. 282-287, 2012.

[15] C. Kwok and G. Sullivan. "The concepts of health and preventive health practices of Chinese-Australian women in relation to cancer screening," $J$ Transcult, vol. 18, no. 2, pp. 118-126, 2007.

[16] A. K. Hackshaw and E. A. Paulo, "Breast self-examination and death from breast cancer: a meta-analysis," Br J Cancer, vol. 88, pp. 10471053,2003
[17] O. Odusanya, O. Olufemi O and O. Tayo, "Breast cancer knowledge, attitudes and practice among nurses in Lagos, Nigeria," Acta oncologica, vol. 40, no. 7, pp. 844-848, 2011.

[18] E. Çeber, M. T. Soyer, M. Ciceklioglu and S. Cimat, "Breast cancer risk assessment and risk perception on nurses and midwives in Bornova health district in Turkey," Cancer Nursing, vol. 29, pp. 244-249, 2006.

[19] S. Memis, N. A. Balkaya and F. Demirkiran, "Knowledge, attitudes, and behaviors of nursing and midwifery students regarding breast Selfexamination 36, no.1, pp. e39, 2009.

[20] M. Kim and Y. Park, "Knowledge, Attitude, and Practice of Obstetric Nurses in Relation to Breast Cancer and Breast Self- examination," Korean Journal of Women Health Nursing, vol. 17, no. 1, 2011.

[21] P. Taymoori and T. Berry, "The validity and reliability of Champion's Health Belief Model Scale for breast cancer screening behaviors among Iranian women," Cancer Nurs, vol. 32, no.6, pp. 465-472, 2009.

[22] D. N. Boulos and R. R. Ghali, "Awareness of breast cancer among female students at Ain Shams University, Egypt," Glob J Health Sci, vol. 6, no. 1, pp. 154-161, 2013.

[23] N. H. Rosmawati, "Knowledge, attitudes and practice of breast selfexamination among women in a suburban area in Terengganu, Malaysia," Asian Pac J Cancer Prev, vol. 11, no. 6, pp. 1503-1508, 2010.

[24] Ö. Karayurt, D. Özmen and A. Çetinkaya. "Awareness of breast cancer risk factors and practice of breast self examination among high school students in Turkey," BMC Public Hlth, vol. 8, pp. 359, 2008.

[25] A. Ayed, F. Eqtait, L. Harazneh, I. Fashafsheh, S. Nazzal, B. Talahmeh and R. Awawdeh, "Breast self-examination in terms of knowledge, attitude, and practice among nursing students of Arab American university," Journal of Education and Practice, vol. 6, no. 4, pp. 37-47, 2015

[26] N. Al-Abadi, "Factors influencing BSE practice among Jordanian nurses," unpublished, 2011.

[27] N. Juanita, P. Jittanoon and U. Boonyasopun, "BSE practice and BSE selfefficacy among nursing students in Aceh, Indonesia," Nurse Media Journal of Nursing, vol. 3, no. 1, pp. 557-568, 2013. 